Revista Letras,

Curitiba, UFPR, n. 94 jun./dez.

2016. ISSN 22360999

\title{
Teoria do Romance e Literatura Menor: Confluências Teóricas para pensar a Literatura Brasileira
}

\author{
Theory of the Novel and Minor Literature: Theoretical \\ Confluences for Thinking Brazilian Literature
}

Silvana Oliveira *

Resumo:

Este artigo se propõe a relacionar duas abordagens teóricas produzidas no âmbito do pensamento de três teóricos do século xx. São eles Mikhail Bakhtin, Gilles Deleuze e Felix Guattari, cujas abordagens dão conta da produção do discurso romanesco e da literatura menor em contextos culturais não hegemônicos. Bakhtin concebe o funcionamento do discurso romanesco pelo aproveitamento de uma dicção familiarizada com o menor, com o baixo, com a língua que ecoa na rua e não nos salões ou vozes aristocráticas; já a literatura menor de Gilles Deleuze e Felix Guattari é apresentada como o uso menor e hierarquicamente desprestigiado que uma minoria faz no seio de uma língua reconhecida culturalmente como superior. Da associação proposta aqui resulta a reflexão de que uma literatura produzida em meio não hegemônico se dá pela ativação de uma força linguística resultante do uso da língua que uma minoria faz em uma língua maior; estende-se essa percepção ao modo de realização literária que uma comunidade de produtores pertencentes a um grupo não hegemônico faz frente ao já avaliado criticamente em contextos culturais dados como mais relevantes histórica e culturalmente.

Palavras-chave: Mikhail Bakhtin, Gilles Deleuze, Felix Guattari

Abstract:

This article intends to relate two theoretical approaches developed in the intellectual scope of three 20th century theorists. They are Mikhail Bakhtin, Gilles Deleuze and Felix Guattari, whose approaches deal with the fictional discourse in novels and the minor literature in non-hegemonic contexts. Bakhtin understands the functioning of the fictional discourse through the exploration of a specific diction related to the minor, to the low, to the voices that echo on the streets and not in the ballrooms of the aristocracy. On the other hand, the concept of minor literature presented by Gilles Deleuze and Felix Guattari refers to the minor and unprivileged use of language that a minority performs in the midst of a linguistic context recognized as culturally superior. From the association therefore proposed it derives a perception that the literature production in a non-hegemonic context is developed through the activation of a linguistic force resulting from the use of a higher language by a minority. Thus, it is possible to extend this perception to the way literature is developed by a community of producers from a non-hegemonic group before what has already been critically evaluated in cultural contexts seen as more relevant both historically and culturally.

Keywords: Mikhail Bakhtin,Gilles Deleuze,Felix Guattari.

\footnotetext{
* Professora associada do Departamento de Estudos da Linguagem da Universidade Estadual de Ponta Grossa, Doutora em Teoria e História Literária pela unicamp e Pós-Doutora em Literatura Comparada pela Universidade do Estado do Rio de Janeiro.
} 
Oliveira, S.

Teoria do

Romance e

Literatura

Menor:

Confluências

Teóricas

para pensar

a Literatura

Brasileira

\section{Introdução}

A o referir-se à abordagem de um autor por outro, Gilles Deleuze faz a seguinte recomendação: "Evitar a dupla ignomínia do erudito e do familiar. Conferir a um autor um pouco dessa alegria, dessa força, dessa vida amorosa e política, que ele soube dedicar, inventar (...)" (Deleuze, 1992). Em atenção ao conselho deleuzeano, ao referir-me aqui à homenagem prestada à professora e pesquisadora Marilene Weinhardt, não me atenho ao valor humano que a convivência e a admiração pessoal evocam; nem também ao vasto material disponível na sua produção atenta e responsável acerca do fenômeno literário associado à leitura do histórico e do social em uma escala invejável para qualquer pesquisador, no Brasil ou fora dele. Atenho-me, sim, ao que sua atuação representa como multiplicadora do pensamento; à sua generosidade capaz de ativar uma ética do compartilhamento acadêmico, de que sou fruto, no final das contas.

Este texto se inscreve, portanto, como produto de uma relação já extensa no tempo, mas, sobretudo, intensa, na medida em que ter frequentado a vida acadêmica e ter privado da personalidade instigante e, novamente, generosa, da professora Marilene Weinhardt produziu em mim a fé de que seria possível fazer associações próprias e atuar com liberdade em relação ao que o mundo da literatura, da teoria e da crítica oferece.

Assim, proponho neste artigo o encontro entre três teóricos que escrevem em tempos diferentes sobre a realização da linguagem em modo artístico, são 
Oliveira, S. Teoria do

Romance e

Literatura

Menor:

Confluências

Teóricas

para pensar

a Literatura

Brasileira

eles Mikhail Bakhtin, Gilles Deleuze e Felix Guattari. Refletir sobre as relações possíveis entre conceitos propostos por teóricos que viveram a fase mais intensa de sua produção em tempo e espaço tão diferentes, como é o caso dos três nomes apresentados, é um desafio que pode, a princípio, parecer temerário. A intenção é fazer com que o aparente anacronismo da perspectiva ative pontos de conexão entre os conceitos em destaque, de forma a esclarecê-los mutuamente e provocar a reavaliação do pensamento de Bakhtin, no sentido em que o situamos em paralelo ao pensamento de dois teóricos pós-estruturalistas. O objetivo específico pretendido neste escrito é refletir sobre a teoria do romance, de Mikhail Bakhtin (1998), em comparação à noção de literatura menor pensada por Gilles Deleuze e Felix Guattari (2002).

Importa antecipar que literatura menor, nos moldes em que é pensada pelos autores nominados, nada tem a ver com literatura de menor valor estético ou de mais fácil compreensão no contexto de uma produção superior em termos artísticos. Para uma boa compreensão da discussão que proponho, interessa que se destaque o sentido de literatura menor não como o da produção em uma língua menor, mas antes como sendo o uso da língua que uma minoria faz em uma língua maior.

Para a ativação teórica aqui pretendida, o aspecto que interessa do escopo da produção de Bakhtin sobre o romance é a sua discussão sobre o discurso romanesco, sistematizada, principalmente, no artigo intitulado Discurso no romance, escrito entre 1934 e 1935, e apresentado em português pela primeira vez, junto com outros textos que tratam do romance como objeto de reflexão teórica, no livro Questões de literatura e estética, editado pela EDUNESP (1998).

\section{Dialogismo, romance e literatura menor}

A abordagem de Bakhtin explicita a seleção do romance como objeto privilegiado de análise. Isso se dá por conta do reconhecimento de uma tradição não-oficial do gênero; Bakhtin propõe um itinerário para a história do romance em que a sua formação passa pela experimentação da língua, alocando aí textos produzidos em variadas condições discursivas, todas elas associadas à condição de uso popular, algo que ele remeteria a uma "tradição prosaica". Tradição esta mantida em desacordo e, em alguns casos, em pleno confronto com o cânone estabelecido; seria necessário, para atender ao que prega Bakhtin, aceitar a realização artística como algo familiarizado com o menor, com o baixo, aquilo que ecoa na rua e não nos salões ou por meio de vozes aristocráticas: 
Oliveira, S. Teoria do

Romance e

Literatura

Menor:

Confluências

Teóricas

para pensar

a Literatura

Brasileira semântico-verbal do mundo ideológico, e que reconheceu a pluralidade das línguas nacionais e, principalmente, sociais, que tanto podem ser "línguas da verdade", como também relativas, objetais e limitadas de grupos sociais, de profissões e de costumes. O romance pressupõe uma descentralização semântico-verbal do mundo ideológico, uma certa dispersão da consciência literária que perdeu o meio linguístico indiscutível e único do pensamento ideológico, que se encontra entre as línguas sociais nos limites de uma única linguagem e, entre as línguas nacionais, nos limites de uma única cultura (helenística, cristã, protestante) de um único mundo políticocultural (reinos helenísticos, Império Romano, etc.) (вакнтім, 1998, p. 164).

A teoria do romance de Mikhail Bakhtin insere no centro do conceito do gênero romanesco a premissa de que ele se realiza na apropriação do alheio, da voz de outrem; disso decorre a revolução mais substancial desse pensamento: ao realizar-se por meio do discurso do outro, o romance revela ou denuncia o caráter plural da língua, da cultura. A problemática apontada tem a ver com a "libertação fundamental das intenções semântico-culturais e expressivas do poder de uma língua única e só e, consequentemente, trata-se da perda da percepção da língua como um mito, como uma forma absoluta do pensamento" (Idem).

Justamente nesses aspectos que destacamos do pensamento de Bakhtin sobre o romance encontramos seus pontos de conexão com o sentido de "literatura menor" apresentado por Deleuze e Guattari ${ }^{1}$.

Gilles Deleuze e Felix Guattari começam a escrever juntos a partir de 1972, com o polêmico Anti-Édipo, a este livro seguiu-se a série não menos provocativa Mil Platôs: capitalismo e esquizofrenia, de 1980, cujos cinco volumes traduzidos apareceram no Brasil a partir de 1995, pela Editora 34. O conceito de literatura menor é desenvolvido pelos teóricos em 1975 para o estudo da produção de Kafka e para sustentar a perspectiva de que a literatura do escritor antecipa o procedimento não representacionista que marcaria a literatura europeia da segunda metade do século XX. O primeiro contato com esse texto se deu pela tradução brasileira de Júlio Castanon Guimarães, apresentada pela Editora Imago em 1977; no momento utilizo a tradução portuguesa de Rafael Godinho, apresentada em 2002, pela Editora Assírio \& Alvim.

Deleuze e Guattari afirmam que a prática da literatura menor aponta para a atuação de um discurso de força política no interior de uma realidade linguística complexa. Ao tratar da produção de Kafka com a intenção de situá-la como a

1 "O que é uma literatura menor?" In: Deleuze, G. \& guatarri, F. Kafka: para uma literatura menor. Tradução de Rafael Godinho. Lisboa: Assírio e Alvim, 2003. p. 38-56.
Revista Letras, Curitiba, UFPR, n. 94 p. $25-35$, jun./dez. 2016. ISSN 2236-0999 
Oliveira, S. Teoria do

Romance e

Literatura

Menor:

Confluências

Teóricas

para pensar

a Literatura

Brasileira manifestação concreta do que chamam de literatura menor, os autores destacam que:

Só o menor é que é grande e revolucionário. Odiar qualquer literatura de mestres. Fascínio de Kafka pelos criados e empregados (caso idêntico em Proust, devido à linguagem, para com os criados). Mas, o que também é interessante, é a possibilidade fazer da sua própria língua um uso menor, supondo que ela é única, que ela seja uma língua maior ou que o tenha sido. Estar na sua própria língua como um estrangeiro: é a situação do Grande Nadador de Kafka ${ }^{2}$. Ainda que única, uma língua é sempre uma caldeirada, uma mistura esquizofrênica, um traje de Arlequim através do qual se exercem funções de linguagem muito diferentes e centros de poder distintos, ventilando o que pode ser e não ser dito: lança-se uma função contra a outra, faz-se funcionar os coeficientes de territorialidade e de desterritorialização relativos (DELEUZe \& GUATTARI, 2002, p. 54-55).

Os autores reconhecem três movimentos definidores dessa prática; o primeiro deles tem a ver com o fato de uma literatura menor não pertencer a uma língua menor, mas, antes, à língua que uma minoria constrói numa língua maior. Esse movimento leva à primeira característica definidora da literatura menor, que é a de que nessa prática a língua é afetada por um forte coeficiente de desterritorialização; o segundo movimento definidor da literatura menor é o de que tudo nela é político. Nas chamadas "grandes literaturas", as questões individuais, das familiares às existenciais, juntam-se a outras questões também individuais e o cenário social e político limita-se a pano de fundo. Na literatura menor, ao contrário, as questões individuais assumem caráter coletivo e político, pois no cerne de uma problemática singular e/ou individual se agita outra, de alcance mais amplo, com complexas conexões.

O terceiro movimento da literatura menor é que nela tudo é coletivo; relativiza-se o talento criativo individual para fazê-lo agir como parte de um agenciamento coletivo de enunciação. A noção de "máquina literária", tão cara a Deleuze e Guattari, funciona bem para se pensar a literatura brasileira na medida em que, por exemplo, parece impróprio que se vistorie a produção de um Guimarães Rosa sem que se debata nela os ecos - críticos e artísticos - de uma

2 O Grande Nadador é com certeza um dos textos mais "beckettianos" de Kafka. "sou obrigado a constatar que estou aqui no meu país e que, apesar de todos os esforços, não compreendo peva da língua em que o senhor fala ..." (Obras completas, V, p. 221) (Nota dos autores Deleuze e Guattari).
Revista Letras, Curitiba, UFPR, n. 94 p. $25-35$, jun./dez. 2016. ISSN 2236-0999 
Oliveira, S. Teoria do

Romance e

Literatura

Menor:

Confluências

Teóricas

para pensar

a Literatura

Brasileira tradição narrativa que se espraia desde os romances de formação europeus até as formas simples das narrativas populares visitadas pelo autor. Não se trata, portanto, de verificar as influências e os predecessores com os quais o autor se alinha, mas sim observar como sua produção é potencializada e conectada a discursividades múltiplas ao mesmo tempo em que se sustenta no cenário cultural brasileiro como ativadora e agenciadora de novas possibilidades de avaliação junto às grandes dicções literárias do seu século. Do menor se faz o maior, como já nos ensinou Machado de Assis, no século anterior a Rosa.

Os movimentos propostos como definidores do conceito de literatura menor, assim como a ênfase de Bakhtin na definição da força política do romance como gênero discursivo, faz pensar na importante formulação de Antonio Candido na sua Formação da Literatura Brasileira: a literatura considerada como um sistema de obras interligadas por denominadores comuns, que permitem reconhecer as notas dominantes de uma fase. Os denominadores comuns capazes de fazer da literatura aspecto orgânico da civilização são mencionados nos seguintes termos:

(...) a existência de um conjunto de produtores literários, mais ou menos conscientes do seu papel; um conjunto de receptores, formando os diferentes tipos de público, sem os quais a obra não vive; um mecanismo transmissor, (de modo geral, uma linguagem, traduzido em estilos), que liga uns a outros. O conjunto dos três elementos dá lugar a um tipo de comunicação inter-humana, a literatura, que aparece sob esse ângulo como sistema simbólico, por meio do qual as veleidades mais profundas do indivíduo se transformam em elementos de contacto entre os homens, e de interpretação das diferentes esferas da realidade (CANDido, 2000, p. 23).

A consciência da prática literária como um agenciamento coletivo de enunciação; o deslocamento da noção de talento individual e o caráter político previsto na proposição da literatura como sistema aproximam as formulações de Antonio Caândido do conceito de literatura menor; destaco, no entanto, a problematização um tanto mais radical que a noção de literatura menor traz para a concepção de sistema na medida em que evoca uma produção de uma minoria linguística e cultural no seio de uma maioria já estabelecida. A aparente impropriedade na aproximação dos conceitos de sistema literário e literatura menor pode ser resolvida se a literatura brasileira for considerada como produto de uma dicção minorizada - em termos políticos e de valoração estética - na relação com a produção literária europeia, mesmo a de língua portuguesa e, num outro viés, se a produção de Guimarães Rosa for aqui tomada como a espiral 
Oliveira, S. Teoria do

Romance e

Literatura

Menor:

Confluências

Teóricas

para pensar

a Literatura

Brasileira

discursiva capaz de transfigurar uma realidade linguística problemática (dadas as suas condições de produção e manifestação); posso considerar, por exemplo, os movimentos da literatura menor para a abordagem do aproveitamento que o autor faz da fala do sertanejo dos vários sertões figurados em sua vasta produção, desde a contística, passando pelas novelas até o surpreendente romance Grande Sertão: Veredas, em que a diç̧ão sertaneja se amplia para tocar nos grandes temas até então associados apenas ao exercício erudito da linguagem.

Ainda nesse sentido, Antonio Candido destaca o aspecto militante da literatura brasileira quando afirma que "a nossa literatura é essencialmente empenhada":

O desenvolvimento do romance brasileiro, de Macedo a Jorge Amado, mostra quanto a nossa literatura tem sido consciente da sua aplicação social e a responsabilidade na construção de uma cultura. Os românticos, em especial, se achavam possuídos, quase todos, de um senso de missão, um intuito de exprimir a realidade específica da sociedade brasileira. E o fato de não terem produzido grande literatura (longe disso) mostra como são imprescindíveis a consciência propriamente artística e a simpatia clarividente do leitor - coisa que não encontramos senão excepcionalmente no Brasil oitocentista (CANDIDO, 2000, p. 26).

Empenho que, até um determinado momento da nossa história literária, tem um caráter moral ingenuamente associado à capacidade de nossos escritores verterem produções originais. Em Machado de Assis: por uma poética da emulação (2013), João Cezar de Castro Rocha aponta com presteza a mudança de rumo operada na obra machadiana quando essa ingenuidade é superada de forma definitiva. Conquanto se verifique, como faz Castro Rocha, que a emulação não é estranha ao universo do Machado anterior a 1890, é o contato direto com um Eça de Queirós cônscio da necessidade de ler e "meter a unha" naquilo que lhe serve de modelo e desafio, que a produção do brasileiro ganha potência e revela o Machado capaz do diálogo cultural de que o Brasil carecia para sustentar de forma madura o empenho em fazer da literatura brasileira uma voz audível.

Machado estabelece um percurso que orienta a produção no século seguinte e de antemão ensina a lição ao Guimarães Rosa leitor e anotador de toda uma tradição europeia, marcadamente a alemã e a francesa - destaquem-se aqui os apontamentos feitos por Suzi Frankl Sperber (1982) sobre as leituras realizadas por Rosa.

Ao deixar-se seduzir pela potência da oralidade como força capaz de contaminar/ativar o discurso literário, a produção de Guimarães Rosa assume o desafio 
Oliveira, S. Teoria do

Romance e

Literatura

Menor:

Confluências

Teóricas

para pensar

a Literatura

Brasileira

marioandradiano de acionar o português brasileiro e fazê-lo cumprir a promessa modernista. Ao falar de si mesmo como incapaz de trazer para o exercício literário a língua brasileira, Mario de Andrade coloca o problema para as gerações futuras no famoso inventário Movimento Modernista:

Caberia aqui também o repúdio dos que pesquisaram sobre a língua escrita brasileira. Preocupados pragmaticamente em ostentar o problema, fizeram tais exageros de tornar para sempre odiosa a língua nacional. Eu sei: talvez neste caso ninguém vença o autor destas linhas. Em primeiro lugar, o autor destas linhas, com alguma faringite, vai passando bem, muito obrigado. Mas é certo que jamais exigiu the seguissem os brasileirismos loquazes. Se os praticou (um tempo) foi na intenção de pôr em angústia aguda um problema que julgava Lins do Rego fundamental. Mas o problema verdadeiro não é vocabular, é sintático. E afirmo que o Brasil hoje possui, não apenas regionais, mas generalizadas no País, numerosas tendências e constâncias que the dão natureza característica à linguagem. Mas isso ficará para outro futuro movimento modernista, amigo José de Alencar, meu irmão. Nós fracassamos. (grifo nosso) (ANDRADE, 2004).

Mario de Andrade parece antever Guimarães Rosa e a empreitada linguística que sua obra assume. Colocando em termos diretos, digo então que o conceito-noção de literatura menor se propõe como necessária reflexão sobre a produção de um autor que quis trazer para o seu universo discursivo o modo de falar brasileiro, sem, no entanto, descuidar do fato de que esse falar brasileiro seria transfigurado em elemento estético. Quando Antonio Candido afirma no famoso ensaio Sagarana, de 1946, que Guimarães Rosa não é um regionalista, descartando o argumento da língua sertaneja, pois em nenhum lugar do Brasil se falava aquela língua, já fomos advertidos para o funcionamento da língua: não se trata de observar e registrar; trata-se, antes, de observar, registrar, transfigurar, associar, dissociar, anotar e colar. Fazer literatura menor, portanto.

A transfiguração intensiva da língua, em seu plano estético e político, pode ser dita como literatura menor, nos moldes em que a apresentam Deleuze e Guattari e autorizam também a evocar a concepção de dialogismo bakhtiniano, cuja realização resulta da tensão que força a língua e a cultura a um movimento centrífugo, de desestabilização, movimento de espiral, uma vez que não há uma autoridade absoluta (ética ou estética) a conferir um princípio único para o discurso romanesco. O romance não reconheceria, no dizer de Bakhtin (p. 82), um centro ao qual manter-se próximo permanentemente, seu movimento por vezes é de aproximação a um centro cultural e canônico, outras vezes é de afas- 
Oliveira, S. Teoria do

Romance e

Literatura

Menor:

Confluências

Teóricas

para pensar

a Literatura

Brasileira tamento.

Essa é sua premissa geral: o romance opera por uma dinâmica dialógica, existe na apropriação do alheio; não há, portanto, uma unidade de cultura que lhe dite a realização. Nessa medida evoco o parentesco do discurso romanesco com a noção de literatura menor, sobretudo no que isso nos adverte quanto ao aspecto político de uma prática literária que se realiza pelo aproveitamento das frestas deixadas pela força do discurso institucionalizado como literário no âmbito de uma cultura.

Ao tomar a tradição prosaica como a matriz do romance, Bakhtin reavalia o itinerário convencional da história do romance e indica o que poderíamos chamar de processo de pasteurização no estabelecimento do cânone ocidental. A teoria do romance de Bakhtin busca corrigir esta equação do clássico ocidental na medida em que propõe o gênero romance como resultado da multiplicidade discursiva da língua em uso.

O romance seria, então, a concretização de uma arquitetura do dialógico, uma vez que ele existe nas fronteiras dos atos discursivos da cultura e se apropria desses atos ao formalizar suas diversas vozes em sua interioridade composicional. Retomamos, com isso, a perspectiva inicial do artigo O Discurso no romance, quando o teórico afirma que

O romance é uma diversidade social de linguagens organizadas artisticamente, às vezes de línguas e de vozes individuais. A estratificação interna de uma língua nacional única em dialetos sociais, maneirismos de grupos, jargões profissionais, linguagens de gêneros, fala das gerações, das idades, das tendências, das autoridades, dos círculos e das modas passageiras, das linguagens de certos dias e mesmo de certas horas (cada dia tem sua palavra de ordem, seu vocabulário, seus acentos), enfim, toda estratificação interna de cada língua em cada momento dado de sua existência histórica constitui premissa indispensável do gênero romanesco. E é graças a este plurilinguismo social e ao crescimento em seu solo de vozes diferentes que o romance orquestra todos os seus temas, todo seu mundo objetal, semântico, figurativo e expressivo (вакнтіл, 1998, Р. 74).

O reconhecimento de que o romance se realiza pela dinâmica de evocar as diferentes vozes de uma cultura de forma a revelar os seus modos de realização em um dado contexto social, inclusive seus desacertos, injustiças e hierarquias, torna possível a associação com a literatura menor deleuzoguattariana, em que uma língua maior, hierarquicamente estabelecida sobre usos menores e menos
Revista Letras, Curitiba, n. 93 p. $52-69$, jan./ jun. 2016. ISSN $2236-$ 0999 (versão eletrônica) 
Oliveira, S. Teoria do

Romance e

Literatura

Menor:

Confluências

Teóricas

para pensar

a Literatura

Brasileira

prestigiados socialmente, é contaminada pelo efeito produtivo da produção que se realiza por meio do uso de línguas menores que pululam no seio da língua do poder instituído. Essas línguas paralelas, moleculares, tem efeito desestabilizador em relação aos valores estratificados de uma visada cultural hegemônica. Daí a força da literatura menor frente à noção convencional de tradição e influência.

\section{Duas conclusões provisórias}

Resulta dessa reflexão uma primeira conclusão que expande a teoria do romance de Mikhail Bakhtin do campo de análise apenas do discurso romanesco, visto que posso tomar suas considerações sobre a prática de escrita específica da produção do romance e considerá-la para a apreciação da produção não apenas do gênero romance, mas sim de um posicionamento político, ético e estético em relação à linguagem e que pode se manifestar na produção de outras narrativas, alocadas em outras modalidades de criação da linguagem, para além da definição do romance. É preciso lembrar que o dialogismo e o descentramento pensados por Bakhtin para a prática da linguagem foram elaborados em uma época anterior à era das tecnologias da linguagem.

Uma segunda conclusão possível para este artigo é a de que a literatura menor pensada por Gilles Deleuze e Felix Guattari figura como uma prática produtiva capaz de revelar a potência estética e política de uma língua naquilo que ela manifesta de menor e popular, próprio, portanto, por consequência. A arquitetura prevista na prática da literatura menor tem em sua concepção a consciência de que é preciso tomar o que é maior e contaminá-lo com o menor e próprio, assim a prática discursiva de um grupo social minoritário encontra espaço de realização junto ao que já está consagrado, como é possível observar nos momentos significativos da realização literária brasileira. 
Oliveira, S. Teoria do

Romance e

Literatura Menor:

Confluências

Teóricas para pensar a Literatura Brasileira

\section{Referências}

ANDRADE, Mario. O Movimento Modernista. Disponível em http://www.vermelho.org.br/noticia/175420-11, consultado em 29 de outubro de 2016.

CANDIDO, Antonio. Formação da Literatura Brasileira. 6. Edição. Belo Horizonte-Rio de Janeiro: Editora Itatiaia, 2000, p. 23.

DELEUZE, G. \& GUATTARI, F. Kafka: para uma literatura menor. Tradução de Rafael Godinho. Lisboa: Assírio e Alvim, 2003.

Pelbart. Rio de Janeiro: Ed. 34, 1992.

Conversações - 1972-1990. Trad. De Peter Pál

Kafka: Por uma Literatura Menor. Trad. Júlio

Castanon Guimarães. Rio de Janeiro: Imago Editora, 1977.

Mil Platôs - capitalismo e esquizofrenia. Vol. 1. Trad. Aurélio Guerra Neto e Celia Pinto Costa. Rio de Janeiro: Editora 34, 1995.

ROCHA, João Cezar de Castro. Machado de Assis: por uma poética da emulação. Rio de Janeiro: Civilização Brasileira, 2013.

Submetido em 16/9/2016

Aceito em 24/9/2016 